\title{
Psychological Interventions for Cancer Patients to Enhance the Quality of Life
}

\author{
Barbara L. Andersen \\ Ohio State University
}

\section{Abstract}

Although the thrust of the nation's cancer objectives for the year 2000 is prevention and screening, each year approximately 1 million Americans are diagnosed and must cope with the disease and treatments. They do so with the aid of family, friends, and the health care system, but accumulating data suggest that psychological interventions may be important for reducing emotional distress, enhancing coping, and improving "adjustment." Experimental and quasi-experimental studies of psychological interventions are reviewed, and discussion of treatment components and mechanism is offered. A final section discusses future research directions and challenges to scientific advance.

\begin{abstract}
In 1989, approximately 985,000 Americans developed cancer, and 494,000 Americans died of the disease (Silberberg \& Lubera, 1989). However disturbing these figures were, they were juxtaposed by a startling Lancet report of the long-term (10-year) follow-up of participants in a psychotherapy outcome study. David Spiegel, Joan Bloom, and their colleagues (Spiegel, Bloom, Kraemer, \& Gottheil, 1989) reported mortality data for 36 no-treatment control and 50 intervention women with metastatic breast cancer who had participated in a group support intervention to enhance adjustment and reduce disease symptoms, such as pain. Their original reports (Spiegel, Bloom, \& Yalom, 1981; Spiegel \& Bloom, 1983; or Spiegel \& Yalom, 1978, and others) had documented adjustment outcomes during the year-long intervention. These and related reports had suggested that gains could be achieved with psychological therapy, even as life ebbed away (Linn, Linn, \& Harris, 1982). However, it would require a leap of faith to hypothesize a psychological or behavioral mechanism to effect any disease endpoint. Thus, when Spiegel reported an 18-month survival advantage for the intervention group, his findings renewed interest in a role for psychological efforts in coping and living with cancer.
\end{abstract}

The Lancet report notwithstanding, the research literature on psychological therapies for cancer patients has had a relatively brief history, although the body of descriptive data documenting the psychological-behavioral outcomes of cancer has grown rapidly (see Andersen, 1989, or Cancer, Vol. 67, No. 3 Supplement [whole issue], for reviews). ${ }^{1}$ The dearth of intervention studies has occurred for a variety of research training and funding reasons (see Andersen, Beck, Ouelette-Kobasa, Revenson, \& Temoshok, 1989, or Burish, 1991a, 1991b, for discussions);

Correspondence concerning this article should be addressed to Barbara L. Andersen, Department of Psychology, 1885 Neil Avenue, Ohio State University, Columbus, Ohio 43210-1222.

${ }^{1}$ The review of psychological efforts with cancer patients for the initial Journal of Consulting and Clinical Psychology behavioral medicine issue focused on behavioral treatments for aversive reactions to chemotherapy (Redd \& Andrykowski, 1982). That literature has progressed in the decade with several cogent, recent reviews devoted to the topic (Andrykowski, 1990; Carey \& Burish, 1988; Carnrike \& Carey, 1990; Morrow \& Dobkin, 1988) in addition to the rapidly progressing research on drug management and combination treatments of nausea and vomiting (Eyre \& Ward, 1984; Morrow, 1989). Although psychologic efforts have been used to reduce these and other disruptive symptomatologies (e.g., anorexia, see Bernstein, 1986; pain, see Turk \& Fernandez, 1990) and produce indirect improvement of adjustment, this article focuses on broad-based interventions to directly enhance general "adjustment" or improve "quality of life." 
however, the dual expertise - cancer and psychotherapy outcome-required of investigators has been noted less often along with the scientific, ethical, and logistic difficulties surrounding research with ill, symptomatic individuals. Nevertheless, randomized demonstration projects, a major accomplishment in research development (Kazdin, 1986), have been conducted. I will begin with a critical review of the literature and conclude with two related discussions, (a) hypotheses of the components and mechanisms for intervention effectiveness and (b) future directions for research.

\section{Review of Psychological Interventions With Cancer Patients}

A classic question in psychotherapy outcome research has been, "What specific treatment, by whom, is most effective for this individual with that specific problem, and under which set of circumstances?" (Paul, 1969). Responding to this query is made difficult by the additional circumstance of cancer. That is, cancer is not one disease but several separate ones, each with multiple etiologies and disparate outcomes. In sum, there is not a prototypic "cancer patient." However, in this review I will highlight variables that may moderate overall risk and responses to psychological interventions. As a beginning point, Table 1 describes aspects of cancer that may affect an individual's risk for psychological and behavioral morbidity.

There is general support for the correlation between the "magnitude" of disease/treatment and psychological and behavioral endpoints across sites of disease. For example, Cella et al. (1987) examined emotional distress in patients with lung cancer and found that a composite score for the extent of disease and physical impairment from treatment best predicted the magnitude of mood disturbance. Body satisfaction (Schain et al., 1983) and overall quality of life (de Haes, van Oostrom, \& Welvaart, 1986) are correlated with extent of treatment for breast cancer. Among individuals receiving surgical melanoma treatment, there is a positive correlation between the magnitude of distress and the depth of the indentation in the local scars (Cassileth, Lusk, \& Tenaglia, 1983). In our research (Andersen, Anderson, \& deProsse, 1989a), the magnitude of sexual morbidity was greatest among the patients treated with combined treatment (i.e., surgery plus radiotherapy), in comparison with either modality alone. Taken together, these data provide conceptual replications of specific cancer characteristics as risk factors for morbidity.

This conceptualization is used to organize the intervention studies into efforts for patients at low, moderate, or high risk. Within each category there are two sections. First, descriptive investigations are briefly summarized to highlight the general adjustment pattern(s) and provide a point of comparison for the findings for the no-treatment control groups. This discussion is limited to the methodologically strongest studies, longitudinal designs with and without comparison groups. Next for the review, studies using a quasi-experimental (e.g., the nonequivalent control group) or an experimental design are included. Studies using other designs (e.g., single-group pretest-posttest, the post-test only design, case reports) are omitted because of their limited scientific value.

To illustrate the concept of morbidity risk and its role in moderating outcome, I begin with the most comprehensive and well-documented outcome study conducted to date. (For this study, all patient and intervention details are included; however, these details for the remaining studies can be found in Table 2.) Published in the Journal of Consulting and Clinical Psychology in 1980, Wayne Gordon and his collaborators (Gordon et al., 1980) used a quasi-experimental design with repeated assessments for a psychosocial intervention for newly diagnosed melanoma, breast, and lung cancer patients. The intervention had three components: education (including teaching about the medical system, disease and treatment side effects, hypnosis and relaxation training to reduce emotional distress), counseling (including support and ventilation of feelings, issue clarification and problem solving and social support), and environmental 
change (referral for additional services and advocacy to health care personnel). The format was individual sessions with a "counselor" (a psychologist, social worker, or psychiatric nurse). The content and number of sessions were allowed to vary and were recorded as process variables. The research design involved a 6-month recruitment period for the first control group, followed by a 12-month recruitment for the intervention, and then a second 6-month control recruitment. There were differential rates of participation (15-16\% of the control and $23 \%$ of the intervention recruitees declined), with refusers being significantly older. In total, 157 intervention ( 65 melanoma, 50 breast, and 42 lung cancer) and 151 control (62 melanoma, 48 breast, and 41 lung cancer) patients participated. Demographics indicated a mean age in years of 48 for the melanoma, 55 for the breast, and 59 for the lung samples. The entire sample was predominantly White (98\%), married (79\%), and high-school educated (96\%) and had an occupation higher than skilled laborer (89\%). Outcome was assessed pretreatment, posttreatment at hospital discharge, and at 3 and 6 months posttreatment using a structured interview. Measures included a problem-oriented survey of 13 life areas (e.g., physical discomfort, mobility, vocation, finances, social concerns, worry) and standardized questionnaires assessing emotional distress, recent life events, health locus of control, and activities of daily living. Preliminary analyses indicated similar rates of attrition (12-13\% across conditions) but dissimilar sources. Control dropouts were more likely to be male, older, less educated, receiving more treatment modalities, and reporting an external locus of control, whereas only intervention dropouts indicated more religious participation.

Cancer groups such as melanoma, breast, and lung patients would have cancer characteristics of low-moderate-, and high-risk groups, respectively. Process data on the "magnitude" of the psychosocial intervention confirmed their differential outcomes. Whereas the mean intervention was 11 sessions of 20 min duration (a total of $3.7 \mathrm{hr}$ ), lung patients were seen for an average of 20 sessions, breast cancer patients for 13 sessions, and melanoma patients for 8 sessions. For emotional distress, the greatest improvement occurred for the lung cancer patients, moderate improvement for the breast, and no differences between the intervention and the control melanoma groups. These findings may have been due to the adjustment pattern for the no-treatment control subjects for each site. The highest levels of continuing distress were found for the lung patients, moderate levels for the breast group, and a rapid, stable decline in distress for the melanoma patients. Regarding outcome for other life areas, the intervention subjects as a group resumed daily activities significantly sooner (by 3 months) than the controls, and activities were more likely to be away from the home (e.g., grocery shopping) than at home (e.g., watching TV). Finally, there was a trend in more of the intervention subjects returning to work ( $74 \%$ vs. $59 \%$ ), with the lowest rates for the lung cancer patients (49\% vs. $73-79 \%$ for the melanoma and breast groups). In summary, this study is notable by its inclusion of a large sample and examination of disease site as a factor, a structured but individualized intervention, documentation of therapy content and process, and diverse outcome assessment. Finally, it provides evidence for the role of disease/treatment variables in moderating psychosocial outcomes.

\section{Low Morbidity Risk}

Overview of descriptive findings-Longitudinal data suggest that when localized disease is controlled and recovery proceeds unimpaired, the severe distress of diagnosis dissipates and emotions stabilize by 1 year posttreatment. In fact, the greatest improvement can be found as early as 3-4 months posttreatment. These were the outcomes of Stage I breast (Bloom, 1987; Vinokur, Threatt, Caplan, \& Zimmerman, 1989) and Stage I and II gynecologic (Andersen, Anderson, \& deProsse, 1989b) patients conducted in the United States and replicated with data from the Netherlands (de Haes et al., 1986) using controlled prospective longitudinal designs and comparisons with benign disease and healthy subjects. This consistency represents replications across site, treatment, and nationality for women with cancer. Unfortunately, 
comparable longitudinal studies, with or without comparison groups, have not been done with men.

Intervention investigations-Two nonequivalent control group designs have provided brief interventions to gynecologic cancer patients. Capone, Good, Westie, and Jacobsen (1980) "provided a crisis-oriented intervention to newly diagnosed women. The structured counseling provided during hospitalization assisted women to express feelings and fears related to their diagnosis or surgery, provided information about treatment sequelae, and attempted to enhance self-esteem, feminity, and interpersonal relationships. For sexually active women, an additional component included sexual information and methods to cope and reduce anxiety when resuming intercourse. Fifty-six newly diagnosed women participated, and a nonequivalent control group was obtained by recruiting previously treated women on followup. Standardized outcome measures assessed emotional distress (both by symptom ratings and the Profile of Mood States (POMS; McNair, Lorr, \& Droppleman, 1971) and self-concept and were supplemented with self-reports of employment and frequency of intercourse. Data were gathered at pretreatment and 3-, 6-, and 12-month posttreatment. For the measures of emotional distress, analyses indicated no differences between groups or within the intervention group. A trend in the percentages of women returning to work favored the intervention participants (e.g., $50 \%$ vs. $25 \%$ at 3 months). In contrast, substantial differences were found in the sexual outcomes across all posttreatment assessments (e.g., $16 \%$ of the intervention vs. $57 \%$ of the control women reported less frequent or no sexual activity at 12 months posttreatment).

The second quasi-experimental investigation was reported by Houts, Whitney, Mortel, and Bartholomew (1986) and examined peer counseling. The structured intervention included encouragement to maintain interpersonal relationships; to make positive plans for the future; to query the medical staff regarding treatments, side effects, and sexual outcomes; and to maintain normal routines. These interventions were delivered in three telephone contacts (one pretreatment and at 5 and 10 weeks posttreatment) and with pretreatment provision of a booklet and coping audiotape. Thirty-two women, 14 intervention and 18 control, newly diagnosed with gynecologic disease participated. The POMS assessed emotional distress, and an experimenter-derived measure assessed coping strategies at pretreatment and 6 and 12 weeks (3 months) posttreatment. Analyses indicated no differences between groups at any point in time. In summary, both the quasi-experimental designs suggested that interventions for gynecologic cancer patients produced limited gains, with the greatest improvement in sexual functioning.

Edgar, Rosberger, and Nowlis (1992) used a repeated measures crossover design to study the timing of intervention delivery. A coping skills intervention was used and included instruction in problem solving, setting goals to increase feelings of control, cognitive restructuring, relaxation training, and information about the hospital and health care system. Over 200 patients who had been diagnosed on average 11 weeks previously were randomized to receive the intervention early $(n=103)$ or late $(n=102)$. Standardized outcome measures were used and assessed anxiety, depression, perception of control, and distress from intrusive thoughts about the illness. The individual difference variable of ego strength was studied as a moderator of outcome. Measures were completed for both groups at baseline, and at 4, 8, and 12 months. Following the baseline assessment, the early group received the intervention and the late group received the intervention following the 4-month assessment. Analyses indicated that both groups improved with time, but there were greater gains, albeit modest ones, for the late intervention group. The greater effectiveness of the late delivery is puzzling, as there are no strong theoretical or empirical bases for the effect. One confounding in the investigation is that the therapists may have been more effective in the intervention delivery by the time they treated the second group of subjects. Additional analyses suggested that the intervention effects were 
strongest for those with lower ego strength scores or more physical debilitation, perhaps because both variables are correlated with higher levels of distress.

There are only four experimental studies with low-morbidity-risk adult cancer patients, and two have small samples. Davis (1986) compared two behavior therapies with a no-treatment control. The first combined electromyography and temperature control biofeedback along with progressive relaxation training. The second treatment was cognitive-behavior therapy, including identifying current concerns, coping through positive problem-solving imagery and positive self-talk, and progressive relaxation training. Twenty-five women with breast cancer (10 biofeedback, 5 cognitive therapy, and 7 no-treatment) participated. Outcome measures were the Spielberger State Anxiety Inventory (STAI; Spielberger, Gorsuch, \& Lushene, 1970) and urinary cortisol measured with a 24 -hr sample, and data were collected pre- and posttreatment and at an 8-month follow-up. Analyses indicated a significant reduction with time in the state anxiety scores but no differential improvement. Cortisol levels for the intervention subjects were significantly lower at the 8-month follow-up only.

Christensen (1983) reported on a focused intervention for adjustment difficulties of mastectomy patients and their partners. The structured program included discussion of the history of the relationship, readings and discussions of the emotional and sexual aspects of mastectomy, disclosure of feelings and fantasies of the self and the spouse, and other exercises (communication training, role playing) to facilitate confronting and solving problems. Twenty women, 10 intervention and 10 no-treatment control, participated. Standardized outcome measures were used and assessed emotional distress (Beck Depression Inventory [BDI]; Beck, Ward, Mendelson, Mock, \& Erbaugh, 1961; and Spielberger STAI), self-esteem, maritial adjustment, sexual satisfaction, and personality (locus of control) and were administered preand posttreatment. Analyses indicated the intervention had modest effects in reducing distress for the breast cancer patients (i.e., significantly lower scores, 8 vs. 12, only on the BDI), but significant improvements in self-reported sexual satisfaction were found from both the woman and her partner. There were no significant differences on the remaining measures.

Finally, the largest investigation for low-risk patients was conducted by Fawzy, Cousins, Kemeny, and colleagues (Fawzy, Cousins, et al., 1990; Fawzy, Kemeny, et al., 1990) and attempted to reduce distress and enhance immune functioning in newly diagnosed and treated melanoma patients. A structured group support intervention included health education (e.g., reducing sun exposure), illness-related problem solving, stress management (relaxation training), and group support. Eighty patients, 40 intervention and 40 no-treatment control, were recruited. Outcome measures assessed emotional distress (POMS) and included an experimenter-derived coping styles inventory and an immunologic assessment (NK cells, Tcell subsets, CD8 and CD4 T cells, and activation markers on the major T-cell subsets) and were collected pretreatment, posttreatment, and at a 6-month follow-up. Despite randomization the control group was significantly younger, 38 versus 45 years, and there was greater distress (significantly higher anxiety, depression, and anger scores on the POMS) and more problematic coping strategies (higher avoidance and distraction) for the intervention subjects. There were no pretreatment immunologic differences. In analyzing the data, analysis of covariance was used. Regarding emotional distress, at posttreatment the intervention subjects reported significantly more vigor on the POMS; there were no differences on the remaining scales. By 6 months, emotional distress had improved further for the intervention subjects with significantly lower total mood disturbance as a result of lower depression, confusion, and fatigue and higher vigor. Coping data indicated that the intervention subjects reported significantly more use of active-behavioral strategies by treatment's end, a pattern that continued with the addition of active-cognitive strategies by 6 months. Regarding the immunologic findings, there was a significant posttreatment difference between the groups in CDS 7 LGLs for the intervention subjects, and follow-up analyses suggested that these changes 
took place in the CDS T-cell subpopulation and not in the NK cells. At 6 months, the difference in LGLs remained significant, but follow-up analyses indicated the increase was seen in CD16 NK cells but not in the CD8 cells, which had been the posttreatment pattern. Other significant changes were found for NK cells (as determined by markers, but not by cytotoxicity) and T cells (a small reduction in mean levels for CD4, whereas CD8 remained unchanged).

Methodology summary-Drawing general conclusions is made difficult by the restricted study samples. Only three sites of disease have been studied (i.e., breast, gynecologic, and skin), which reflect $3 \%$ of the new cases in men and $47 \%$ of the new cases in women annually (Boring, Squires, \& Tong, 1992). Related to this issue is the circumstance of gender, as only one study included any men (47\% of the sample in Fawzy, Cousins, et al., 1990, and Fawzy, Kemeny, et al., 1990) whereas men represent 50\% of all new cases (Boring et al., 1992). The samples were also not representative of national data on the sociodemographic characteristics of cancer patients. Non-Whites were poorly represented. The Capone et al. (1980) investigation was the only one to include significant numbers of Black women (21\% of the sample). Study samples have been young, as the mean age for the breast sample in Christensen (1983) was 40 years, and the mean age for the melanoma sample in Fawzy, Cousins, et al. (1990) and Fawzy, Kemeny, et al. (1990) was 42 years, in comparison with mean ages of 55 years and 57 years, respectively, from national data (Axtell, Asire, \& Meyers, 1976). These study group characteristics may be due in part to the research sites - university medical centers or a regional cancer center-for all of the investigations except one (Christensen, 1983).

The majority of the studies began during the diagnostic or immediate posttreatment period. Outcome was assessed by a variety of strategies; however, the domains that could be changed through the intervention included self-reports of emotional distress (e.g., POMS, BDI, STAI), coping, and target areas of vulnerability (e.g., sexuality or marital adjustment for women with breast or gynecologic cancer). Other life areas that might be less likely to be affected (e.g., employment status, self-esteem) yielded mixed results. The descriptive data and the quasiexperimental designs confirm the hypothesized profile of low psychosocial morbidity. The rapid emotional rebound that occurs without intervention may have contributed to the findings of no differential outcome (Capone, Good, Westie, \& Jacobsen, 1980; Davis, 1986; Houts et al., 1986) or only modest improvement (Christensen, 1983; Edgar, Rosberger, \& Nowlis, 1992; Fawzy, Cousins, et al., 1990) in emotional distress. Despite this, longer term follow-up data suggested some consolidation of intervention effects across time (upward of 6 months posttreatment), with lowered emotional distress or enhanced coping (Fawzy, Cousins, et al., 1990) coupled with confirming biologic outcomes (Davis, 1986; Fawzy, Kemeny, et al., 1990). Multiple posttreatment assessments (e.g., 3, 6, and 12 months posttreatment in Capone et al., 1980) provide an estimate of the reliability of these effects for a particular study. If longterm outcomes are replicable, they are made more impressive by their achievement with very brief therapy (e.g., 10 therapy hours). Unfortunately, no clear statements can be made regarding the types of therapists who can achieve these gains, as their training ranged from bachelors to doctoral level with several disciplines (e.g., psychology, psychiatry, nursing, social work) represented.

\section{Moderate Morbidity Risk}

Overview of descriptive findings-Psychosocial adjustment is variable for individuals with regional disease. Such were the outcomes in retrospective (Cella \& Tross, 1986) and longitudinal (Devlen, Maguire, Phillips, Crowther, \& Chambers, 1987) studies of Hodgkin's disease and non-Hodgkin's lymphoma patients. Studies of cancer patients receiving adjuvant therapy or single-, double-, or triple-agent chemotherapy report higher levels of affective distress while on therapy than those receiving no treatment or time-limited treatment such as radiotherapy (Hughson, Cooper, McArdle, \& Smith, 1986; Meyerowitz, Watkins, \& Sparks, 
1983). Also, the extensive literature on aversive reactions to chemotherapy (see Carey \& Burish, 1988, for a review) documents the difficult experience of those undergoing cancer treatment for regional disease.

Intervention investigations-The single quasi-experimental design with moderate morbidity risk patients was conducted by Heinrich and Coscarelli-Schag (1985) using stress and activity management, cancer education, relaxation training, cognitive therapy and adaptive coping, and activity management. Fifty-one patients, 26 intervention and 25 control, completed several outcome measures, including ones for emotional distress (Symptom Checklist-90 [SCL-90]; Derogatis, 1977) cancer information, psychosocial adjustment to illness, the Karnofsky Performance Status Scale (Karnofsky \& Burchenal, 1949), reports of daily activities, and self-report ratings of satisfaction with care and quality of life. Data were collected pre- and post-treatment and with a 2-month telephone follow-up. Concerning cancer information, all patients significantly improved with time, but the intervention subjects evidenced differential gains. Regarding emotional distress, psychosocial adjustment, and daily activities, all patients improved with time, but no differential improvement was found. There was no evidence for lowered levels of distress for the spouses across time or with the intervention.

Five diverse experimental investigations have been conducted. In the majority, patients continued in their treatment, chemo- or radiotherapy, during the psychological intervention. Jacobs, Ross, Walker, and Stockdale (1983) conducted two studies, one examining patient education and the other group support, for adults with Hodgkin's disease. One hundred five adults participated who were receiving or had recently completed chemotherapy. A single outcome, an experimenter-derived measure of distress, social adjustment, and life satisfaction, was administered pre- and posttreatment. A knowledge test of Hodgkin's disease was also used for the education study. Subjects were randomized to one of four groups: education intervention $(n=21)$, education control $(n=26)$, support intervention $(n=16)$, or support control $(n=18)$. In the education study, the intervention consisted of provision of a booklet about the disease/ treatment and mailings of brief newspapers about advances in treatment. Analyses indicated that educational intervention subjects significantly improved on the measure of Hodgkin's disease knowledge. Significant improvement was also found on 2 (lower anxiety and fewer treatment problems) of the 14 adjustment scales. In the peer support study, analyses indicated positive psychosocial gains across time but no differential improvement for the intervention patients.

Several articles by Maguire and colleagues (Maguire, Brooke, Tail, Thomas, \& Sellwood, 1983; Maguire, Hopwood, Tarrier, \& Howell, 1985; Maguire, Tait, Brooke, Thomas, \& Sellwood, 1980) have described the outcomes following individual counseling for women treated with mastectomy. A nurse specialist provided an intervention in the hospital presurgery and in the patient's home every 2 months until "it was clear that the patient had adapted well." The intent was to restore mobility to the affected arm through movement exercises, to facilitate adjustment to the scar and breast loss by disclosing feelings, and to encourage to return to social activities and employment. One hundred fifty-two women, 75 intervention and 77 no-treatment control, participated. Outcome measures were experimenter-derived and assessed physical rehabilitation outcomes (e.g., arm swelling, pain) and nurse judgments about social adjustment, return to work, marital adjustment, emotional distress, and sexual functioning, at 3 months and 12-18 months posttreatment. Physical outcomes appeared to be better for the counseled women, with fewer reporting problems with swelling or pain. Psychological responses to breast loss were judged to be better for the counseled women (68\% vs. $52 \%$ had adapted "well"). Also, counseled women reported fewer difficulties with their social relationships and when returning to housework or employment. There were significantly more episodes and more severe episodes of anxiety or depression (e.g., $3 \%$ vs. 19\% of the intervention and control 
groups, respectively, had "moderately severe" bouts of anxiety at 12-18 months). Finally, marital and sexual adjustment was also better for the counseled women. Only $7 \%$ of the experimental but $15 \%$ of the control marriages were "strained" by the illness and treatment, and by $12-18$ months $8 \%$ of the experimental but $31 \%$ of the control women still reported sexual difficulties.

Cain, Kohorn, Quinlan, Latimer, and Schwartz (1986) compared individual and group therapy formats for a structured intervention for women with gynecologic cancer. The intervention had eight components including discussion of the causes of cancer at diagnosis, impact of the treatments) on body image and sexuality, relaxation training, emphasis on good dietary and exercise patterns, communication difficulties with medical staff and friends/family, and setting goals for the future to cope with uncertainty and fears of recurrence. Seventy-two women (21 individual intervention, 22 group intervention, and 29 no-treatment control) participated. Outcome measures were standardized and included depression and anxiety interviewer rating scales and a psychosocial adjustment to illness scale, which were administered pre- and posttreatment and at a 6-month follow-up. Posttreatment analyses indicated all groups improved with time; however, interviewer rated anxiety was significantly lower for the individual therapy subjects only. Gains were more impressive with the 6-month follow-up data. There were no differences between the intervention formats, but both groups reported less depression and anxiety and better psychosocial adjustment (including health perspectives, sexual functioning, and use of leisure time) than the no-treatment control group.

Forester, Kornfeld, and Fleiss (1985) provided individual psychotherapy to cancer patients during radiotherapy. Unlike many other structured interventions, individual psychotherapy sessions were offered to discuss "whatever the patient wished;" Sessions included supportive therapy with "educational, interpretive, and cathartic components" (p. 23). One hundred patients (48 intervention and 52 no-treatment control) completed the study. A standardized interview (modified Schedule for Affective Disorders and Schizophrenia [SADS]; Endicott \& Spitzer, 1978) was administered pretreatment, mid-radiotherapy (3 weeks), end of radiotherapy (6 weeks), postintervention, and at 1- and 2-month follow-ups. Using simple totals of SADS emotional distress symptoms, analyses indicated all groups improved with time, but the psychotherapy patients improved differentially through the 2-month follow-up. Simple totals of SADS physical symptom items - anorexia, fatigue, and nausea/vomiting — indicated significantly lower levels across all symptoms for the intervention group at the 1-month followup only.

Telch and Telch (1986) compared the effectiveness of coping skills instruction with supportive therapy offered in groups for cancer patients receiving routine follow-up care. A novel aspect is that potential participants were screened using an experimenter-derived structured interview, and only those with "clear evidence of psychological distress" (p. 803) were eligible. The intervention taught cognitive, behavioral, and affective coping strategies and included homework assignments, goal setting, self-monitoring, and role playing. Relaxation training and stress management skills were also included, and patients were asked to provide ratings of home practice. The group support intervention provided an environment for patients to discuss feelings, concerns, and problems, with no specific agenda or plan for at-home activities. Forty-one cancer patients (13 coping skills group, 14 group support, and 14 no-treatment control) completed the study. Posttreatment outcome measures were the POMS, the Cancer Inventory of Problem Situations (Heinrich, Coscarelli-Schag \& Ganz, 1984), and an experimenter-derived self-efficacy scale. Despite randomization, pretreatment analyses indicated that subjects in the coping skills intervention reported significantly more distress on the POMS and lower levels of coping efficacy, and analysis of covariance was used. Analyses for the POMS indicated that the coping skills group improved significantly across all scales, the group support group improved on the anxiety and depression scales only, but the no- 
treatment control worsened. The same pattern was found with the other measures. Also, the coping skills patients were rated as being significantly less distressed on both therapist and independent observer ratings than support group and no-treatment control patients, whose ratings did not differ. Despite the differential improvement of the intervention groups, patient ratings of treatment credibility indicated no difference between the groups in their satisfaction with therapy content or the therapists.

Methodology summary-The elevated-risk profile for these patients is evident by the significant distress at study entry even though many had been diagnosed months previously. One source of distress is continued involvement in treatment, as subjects from half of the studies were still receiving radiotherapy or chemotherapy (Heinrich \& Coscarelli-Shag, 1985; Jacobs et al., 1983; Forester, Kornfeld, \& Fleiss, 1985). Participants were more representative on disease and sociodemographic variables. Three studies included a variety of cancer sites (Heinrich \& Coscarelli-Shag, 1985; Forester et al., 1985; Telch \& Telch, 1986) or a previously unstudied site (i.e., Hodgkins disease; Jacobs et al., 1983). Three studies included equal numbers or a predominance of men (Heinrich \& Coscarelli-Shag, 1985; Jacobs et al., 1983; Forester et al., 1985), and the age means for some were more representative (e.g., 59 years for the gynecologic sample in Cain et al., 1986). However, it is likely that the study samples remained largely White, as all but one study (Heinrich \& Coscarelli-Shag, 1985) failed to even report racial data. As for the studies with low-risk patients, all the investigations were conducted at university medical centers (or a Veterans Administration affiliate).

A wider variety of outcome measures detected improvement. Intervention effects were found reliably with self-reports of emotional distress and with modified versions of diagnostic interviews (SADS) or interviewer rated distress (Hamilton Rating for Depression). Unlike the weak effects at posttreatment for low-risk interventions subjects, more impressive posttreatment gains were found initially (excepting Heinrich and Coscarelli-Shag, 1985, and the group support intervention in Jacobs et al., 1983), and the effects appeared stronger with follow-up (Cain et al., 1986; Forester et al., 1985; Maguire et al., 1983), which extended as long as 12 months posttreatment. Interventions with an informational component improved patients' knowledge about their disease and treatment(s) and could be detected with experimenter-derived measures. Outcomes in other areas, such as listings of common concerns or activities of daily living, were more difficult to detect. Despite their relevance, there was only modest measurement of disease or treatment symptomatology, but some interventions did appear to lower symptom levels either directly (e.g., Maguire et al., 1983) or indirectly (e.g., Forester et al., 1985). As with the low-risk studies, brief interventions were offered by a diversity of professionals. Notably, two studies provided important data on treatment credibility and satisfaction with the therapists (Heinrich \& Coscarelli-Shag, 1985; Telch \& Telch, 1986).

\section{High Morbidity Risk}

Overview and descriptive findings-Individuals with systemic or rapidly progressing disease (e.g., pancreatic cancer) confront a life time line of months, as survival for the next year is possible but unlikely (e.g., 1-year rates for metastatic lung, breast, pancreatic, and liver cancers are 39\%, 44\%, 17\%, and 32\%, respectively; Axtell, Asire, \& Meyers, 1976). This situation is devastating, and the magnitude of distress with recurrence eclipses that found with the initial diagnosis (Thompson, Andersen, \& De-Petrillo, 1992). Studies that have contrasted cancer patients showing no evidence of disease (i.e., low risk) and those receiving palliative treatment (i.e., moderate risk; Cassileth et al., 1985) have reported the greatest distress for those with disseminated disease (i.e., high risk; Bloom, 1987). In addition, there is often increasing physical debilitation or difficult-to-manage symptoms, such as pain. 
Intervention investigations-Despite the challenges in conducting research with this population, six experimental studies have been conducted. Ferlic, Goldman, and Kennedy (1979) published the first randomized intervention study, an interdisciplinary crisis intervention program that included patient education, presentations by medical team members, and supportive group therapy. Sixty adults, 30 intervention and 30 no-treatment control, with "advanced" cancer participated. Outcome measures were experimenter-derived and assessed hospital adjustment, communication with others, disease information, death perceptions, and self-concept. Analyses indicated the intervention group improved across all areas, whereas the controls improved in three-relationship strength, cancer information, and death perceptions -following the 2-week intervention. The self-concept score for the intervention group significantly increased, whereas that for the control group significantly decreased. A 6-month follow-up was attempted; however, there was significant mortality (18\%) and insufficient questionnaire returns (55\%).

As noted in the introduction, several papers have described the group support intervention of Spiegel, Bloom, and colleagues (Spiegel et al., 1981; Spiegel \& Bloom, 1983) for women with breast cancer. Women were randomized to no treatment or a group treatment intervention that included discussion of death and dying, family problems, communication problems with physicians, and living fully in the context of a terminal illness. The intervention subjects were also randomized a second time to two conditions: (a) no additional treatment or (b) selfhypnosis for pain problems (Spiegel \& Bloom, 1983), which was incorporated into the weekly intervention. At the end of the first year the groups formally ended, but members could continue to meet as they wished or were able; some groups lasted for an additional 2 years. Eighty-six women, 50 intervention and 36 no-treatment control, participated. Following random assignment, there was subject loss (e.g., refusal, too weak, death) with the study beginning with 34 intervention and 24 control participants; however, the survival data is reported for the original sample of 86. Outcome measures were the Health Locus of Control Scale, the POMS, a phobia checklist, a self-esteem measure, and experimenter-derived measures of maladaptive coping and denial, and they were administered pretreatment and at 4,8, and 12 months during the intervention/control year. In analyzing the treatment outcome data, slopes analysis was used to maximize the use of the data collected, as only $52 \%$ of the subjects completed all assessments. Analyses indicated that the intervention group reported significantly fewer phobic responses and lower anxiety, fatigue, and confusion and higher vigor on the POMS than did the control subjects. These differences were evident at all assessments, but the magnitude increased from 4 to 12 months. There was also a significant decrease in the use of maladaptive coping responses by the intervention group. There were no significant differences on the remaining measures. Regarding the findings from the hypnosis substudy, women receiving hypnosis within the group support intervention reported no change in their pain sensations during the year, whereas pain sensations significantly increased for the other women in group support who did not receive hypnosis. Similar findings were reported for pain suffering-a slight decrease for the women who also received hypnosis and a significant increase in suffering for the remaining intervention women. It is important to note that pain sensation scores for both groups were, however, significantly lower than those for the no-intervention control subjects, suggesting that the hypnosis component provided an additive analgesic effect to other group treatment components. Using the Cox proportional hazards model (Spiegel et al., 1989), a striking difference of 18.9 months for the control subjects and 36.6 months for the intervention subjects was found from study entry until death. Follow-up analyses, controlling for initial disease stage, days of irradiation, or use or androgen or steroid treatments all indicated the same substantial survival differences.

The remaining four investigations included primarily lung cancer patients. The most psychological study was that of Linn, Linn, and Harris (1982). A supportive death-and-dying intervention program was offered to reduce denial but maintain hope, to increase environmental 
control, to continue meaningful activities, and to foster self-esteem and life satisfaction. In addition, the therapist was often with the intervention subject at death. One hundred twenty men were randomized to intervention $(n=62)$ or no-treatment control $(n=58)$ groups. Standardized outcome measures included emotional distress (depression scale from the POMS), self-esteem, life satisfaction, social isolation, and locus of control scale. Nurses rated functional status for daily activities, and a physician rated body system impairment. Measures were administered pretreatment and 1, 3, 6, 9, and 12 months later. There were no significant differences between the groups at the 1-month assessment, but significant differences in favor of the intervention emerged by 3 months and remained for the majority of the measures.

Differences included lower POMS depression score at 3 months, higher life satisfaction, higher self-esteem, lower alienation from 3 to 12 months, and a more internal locus of control for the 9- and 12-month assessments. The results for the lung and other site samples were similar. Despite the more favorable psychological outcomes for the intervention subjects, there were no functional status, body system impairment, or treatment compliance (e.g., rehospitalization, complications) differences between the groups. By the 6-month assessment, 58\% of the sample had died. Survival analyses showed no significant differences between groups.

Two investigations incorporating psychological techniques in the context of specialized nursing care for terminal patients provide relevant data. The no-treatment control condition for both investigations consisted of routine outpatient visits for monitoring medical and psychosocial difficulties. The first study was conducted by Yates, McKegney, and Kun (1981) and compared standard follow-up with monthly home visits by a nurse practitioner providing nursing, pain management, and nutritional services. One hundred ninety-nine patients were randomized to intervention $(n=98)$ or no-treatment control $(n=101)$ groups. Outcome measures were modest and included a visual analog pain rating, a self-report measure of life satisfaction, and the Karnofsky Performance Status Scale (Karnofsky \& Burchenal, 1949). Measures were administered pretreatment and with monthly evaluations by a social worker or, during the latter years of the study, by independent evaluators because it appeared that the social workers began to provide psychosocial interventions despite prohibitions. Few significant differences between the groups were found, with the most notable finding being the stabilization of pain for the home care group with increasing pain for the routine care group. Although the economic costs of the intervention were demonstrated (i.e., more of the home care patients died at home, resulting in lower overall costs), there was no survival advantage for the home care group.

The second nursing intervention was conducted by McCorkle and colleagues (1989) and compared standard office care with two types of specialized home care: visits by a member of an interdisciplinary team and visits by an oncology nurse practitioner. One hundred sixty-six patients with lung cancer were randomized. Standardized outcome measures assessed mood (POMS), current adjustment concerns, need for assistance, and pain, other symptoms, and general health, and were administered pretreatment and every 6 weeks for 6 months. The majority of the subjects died before completion of the study; data analyses are reported only for the 78 subjects ( $47 \%$ of the total) with complete follow-up data. There were no significant pretreatment differences in the areas of mood, current concerns, or pain reports; but despite randomization, there were significant pretreatment differences between groups (better adjustment for the oncology home care group) for the remaining measures, and covariance analyses were used. Analyses indicated significant differences between the specialized home and standard office care models but no differences between the two home care variants. All patients became more debilitated with time, as indicated by increased distress with symptoms, increased dependency, and more negative health perceptions; however, these responses stabilized for the specialized home care groups before increasing to the range of those for the office care group at the final assessment. The only significant finding differentiating the two 
specialized programs was a trend for rehospitalization stays to be shorter (e.g., 50 vs. 76 days) for the patients visited by the oncology nurse.

Methodology summary-Among the methodologic challenges, subject loss (usually from death) is salient, as it may even occur during the time from recruitment to study initiation. Researchers typically compare the initial participants and the "completers" (e.g., Spiegel et al., 1989), and no systematic bias is usually detected. However, if psychological variables are related to survival, then patients surviving longer may be "hardier" on some psychosocial dimension that may interact with treatment involvement. When conducting analyses across time, some investigators have chosen a slopes analysis to maximize the number of data points available for each subject (Spiegel et al., 1981). A less satisfactory solution is to eliminate subjects with incomplete data, as this results in a substantial reduction of statistical power (e.g., McCorkle et al., 1989) and increases the cost of already expensive studies.

Despite these problems with subject mortality, the study participants have been generally representative of adults with advanced or progressive cancer. The study that provided few sociodemographic data but described the patients as having "advanced" disease had the youngest study sample (mean age of 48 years; Ferlic et al., 1979), whereas the mean ages for the remaining studies ranged from 54 to 65 years. With the exception of the breast study by Spiegel and colleagues (1989), the remaining study samples were at least $50 \%$ male, with the Linn study including all men. Studies also included a variety of disease sites. Unfortunately, non-Whites remained underrepresented, with only $11-12 \%$ of the samples being Black in the two studies providing data (Linn et al., 1982; McCorkle et al., 1989). Like all other studies, patients were recruited from university or university-affiliated facilities, with the exception of the participants in the McCorkle et al. (1989) study, who came from several city hospitals.

The positive outcomes for high-risk cancer patients are notable considering their worsening pain and/or increasing debilitation as they approach death. Measures of emotional distress have been found to be sensitive to posttreatment improvements as well as gains with follow-up. In addition, change in other areas-self-esteem/concept, death perceptions, life satisfaction, and locus of control-were more often found (e.g., Ferlic et al., 1979; Linn et al., 1982); these effects were not detected in studies with low-risk patients. Important for quality of life, psychological interventions could also lower or stabilize pain reports (Spiegel \& Bloom, 1983). Finally, it is important to note that the only study in this group that offered brief intervention (9 hr of total therapy time) was Ferlic et al. (1979), whereas the remainder were "several sessions," "until death," or at least $75 \mathrm{hr}$. Again, a diversity of professionals provided the interventions; however, the two studies with the weakest outcome had modest psychological components provided by nurse specialists (McCorkle et al., 1989; Yates et al., 1981).

\section{Intervention Effectiveness: Components and Mechanisms}

Psychological interventions with cancer patients have addressed three phases in the disease time line: diagnosis/pre-treatment, immediately posttreatment or during extended treatment (such as radiotherapy or chemotherapy), and disseminated disease or death. Typically, interventions were designed to address only the adjustment difficulties of a specific phase and were usually so time-limited that little overlap was possible. Although not a perfect correspondence, there has been a "matching" between the interventions for specific phases and the risk groups studied. That is, the majority of the study participants in the diagnostic/ pretreatment studies included low-risk patients, studies of coping with treatment included moderate-risk, and, not surprising, studies of adjustment to disseminated disease or coping with death included high-risk patients. Although there appear to be unique intervention components for different phases, there are some commonalities. 
Studies with newly diagnosed cancer patients have focused on the trauma of learning one has a potentially life-threatening illness. Despite some improvement in cancer prognoses in the last 30 years (e.g., there has been a 70\% decline in cervix death rates and a 33\% decline in liver death rates; American Cancer Society, 1992), Weisman and Worden's (1976-1977) label of existential plight remains descriptive of the emotional, cognitive, and behavioral turmoil. Both descriptive and intervention study data suggest a psychotherapeutic model of crisis intervention or brief therapy as the "best fit." Both are similar in terms of their rapid early assessment, present-day focus, limited goals, therapist direction, and prompt interventions (Kolotkin \& Johnson, 1983). When applied in the context of cancer, therapy components have included an emotionally supportive context to address fears and anxieties about the disease (e.g., Cain et al., 1986; Capone et al., 1980; Forester et al., 1985; Maguire et al., 1983), information about the disease and treatment (e.g., Cain et al., 1986; Fawzy, Cousins, et al., 1990; Fawzy, Kemeny, et al., 1990; Houts et al., 1986; Jacobs et al., 1983; Maguire et al., 1983), behavioral coping strategies (e.g., role playing difficult discussions with family or the medical staff; Fawzy, Cousins, et al., 1990; Fawzy, Kemeny, et al., 1990; Houts, Whitney, Mortel, \& Bartholomew, 1986), cognitive coping strategies (Cain, Kohorn, Quinlan, Latimer, \& Schwartz, 1986; Davis, 1986; Houts et al., 1986; Telch \& Telch, 1986), and relaxation training to lower "arousal" and/ or enhance one's sense of control (Davis, 1986; Edgar, Rosberger, \& Nowlis, 1992; Fawzy, Cousins, et al., 1990; Fawzy, Kemeny, et al., 1990). Also, focused interventions incorporating the above components for areas of increased morbidity for selected disease groups (e.g., sexual functioning for women treated for gynecologic or breast cancer; fertility loss for men treated for testicular cancer) have been included.

The multiple studies using some or all of these components have provided conceptual replications of their effectiveness. These positive outcomes can also be contrasted with null findings for (group) interventions that included no structured content. Reliance on group support alone may be insufficient to produce any measurable benefit (Jacobs et al., 1983; Telch $\&$ Telch, 1986). ${ }^{2}$ Other data also provide clarifying information. The components appear to be more important than procedural variations. For example, therapy format appears to have a lesser impact, as these components have yielded favorable outcome whether delivered individually or in groups (e.g., Davis, 1986; Fawzy, Cousins et al., 1990; and Fawzy, Kemeny et al., 1990, for low risk; Maguire et al., 1980, and Forester et al., 1985, for moderate risk), and same-study contrasts of individual and group formats yielded equivalent improvement (Cain et al., 1986). Involvement of significant others may have some positive effects, but their participation appears to be unnecessary to achieve gains for the cancer patients. (As an aside, direct benefit for a spouse may be minimal [e.g., Heinrich \& Coscarelli-Shag, 1985] unless the focus of treatment is on a mutually important issue, such as sexual problems [Christensen, 1983].) Finally, when distress is declining across time during recovery, as it does for low-and some moderate-risk individuals, it is unclear whether delivery of intervention "late" in the process rather than "early" is beneficial.

What are the mechanisms for intervention effectiveness when delivered during the diagnostic, treatment, or early recovery periods? In large measure, the psychologic mechanisms may not be significantly different from those for coping with other stressors. That is, learning more about a stressor, confronting it with positive cognitive states, active behavioral strategies, and, eventually, reduced emotional distress may provide realistic appraisals of current or impending stresses of the disease or treatment process and enhance one's sense of self-efficacy or feelings of control early in the adjustment process.

\footnotetext{
${ }^{2}$ Some might consider the group-support-only condition in these studies as a conceptual approximation to a placebo condition. As such, the importance of the specific components is further highlighted.
} 
That the interventions produce more than situational improvement and may alter an individual's longer term psychologic/behavioral adjustment is suggested by the gains continuing (and often increasing) during the first posttreatment year (e.g., Cain et al., 1986; Forester et al., 1985), even when the therapy has been brief (e.g., $10 \mathrm{hr}$ total). Also, long-term outcomes may be more easily achieved with the extended interventions. Regardless of the length of the intervention, the continuation of active behavioral coping, positive cognitions, and so forth, may be the type of necessary conditions to enable late mechanisms, psychologic/ behavioral, or biologic, to emerge. For example, a behavioral mechanism hypothesized for the Spiegel et al. (1989) results is that direct effects of the intervention (lower levels of emotional distress and maladaptive coping as well as containment of pain symptom levels) increase the likelihood and success of subsequent adaptive health behaviors (e.g., complying with medical therapy; improving diet, exercise), which may have, in turn, influenced the disease process.

The oft proposed biologic mechanism for findings such as Spiegel et al.'s (1989) is immune system enhancement. Evidence for its plausibility comes from two lines of data. First, some of the specific components highlighted above have been used singly with healthy subjects and positive immune system changes have been found. So it is not inconceivable that similar immune system enhancement might occur for cancer patients if the system is not overburdened/ compromised from the disease or treatment. Specifically, relaxation with medical students before exams (Kiecolt-Glaser et al., 1984) and older adults in retirement facilities (KiecoltGlaser et al., 1985) has produced higher helper T-lymphocyte percentages and higher NK cell activity, respectively. Experimental study of self-disclosure of earlier traumatic experiences from healthy undergraduates found a higher mitogen response in disclosers and, furthermore, a better lymphocyte proliferative response for first-time disclosers (Pennebaker, KiecoltGlaser, \& Glaser, 1988). Although there may be notable differences between disclosure of earlier traumas and active participation in a psychologic intervention, the magnitude of crisis reactions generated by a cancer diagnosis (or the circumstance effacing a rapidly approaching death) may increase their similarities. Second, the most relevant supporting data are those of Fawzy, Cousins, et al. (1990) and Fawzy, Kemeny et al. (1990; see above), who used the intervention components with melanoma patients and found significant and positive immunologic changes. Also, the majority of these changes did not occur until 6 months, a time line consistent with the possibility that longer term behavioral/psychologic processes may be needed to effect immunologic change in a sample with disease.

In addition to the intervention components noted above, other ones (and, correspondingly, other mechanisms) may be operative for high-risk patients. Whereas many cancer patients at low or moderate risk for adjustment difficulties may improve without intervention, high-risk nointervention patients worsen (McCorkle et al., 1989; Spiegel \& Bloom, 1983). The reasons for this more difficult trajectory may include the existential distress that comes with cancer diagnosis in addition to the more difficult confirmation of a shortened life span, increased numbers and less controllable symptoms of disseminated disease or more toxic therapies, and a worsening of the latter difficulties with time.

Intervention for high-risk patients had many of the same components as those for low- or moderate-risk groups, but the more difficult circumstances appeared to shift content to specific death or quality of life issues. For example, coping with one's own (or a group member's) death or decisions of no treatment versus a toxic regimen became therapy tasks (Cassileth \& Cassileth, 1983; Spiegel \& Glafkedes, 1983). Other interventions focused on coping with debilitation or behavioral control of pain (Spiegel \& Bloom, 1983). The psychologic mechanisms underlying the effectiveness of these therapy components may be as described above-enhanced self-efficacy, control, and realistic appraisals. However, additional ones may occur because one's worst fears of cancer (e.g., intolerable symptoms, physical debilitation and dependency, and dying) are often realized. Unavoidable circumstances of this sort may 
make the maintenance of self-efficacy or feelings of control fleeting. What other factors might then contribute to improved outcome for high-risk patients? One possibility is the benefit that accrues from the provision of social support by a therapist.

Interventions for high-risk patients were demanding. Studies noted that therapists needed to be comfortable with difficult topics and circumstances, such as bedside counseling (see Linn et al., 1982, or Spiegel \& Yalom, 1978, for discussions). As patients must cope, these therapists do so as they maintain relationships with those about to die. Variables historically viewed as the critical ones for therapist effects in psychotherapy process and outcome researchempathy, warmth, and genuineness (Parloff, Waskow, \& Wolfe, 1978) - may take on added significance in the context of cancer. Although there are many therapist variables that may be important, these have been universally accepted by all psychotherapy persuasions (Beutler, Crago, \& Arizmendi, 1986). They may be pivotal for cancer patients who are confronting life and death issues when they feel least able or when significant others are unable to do so. When group therapies "work," the role of the therapist (and these qualities) shift to the group participants (Yalom, 1975). The hypothesis for the importance of therapeutic relationships is consistent with epidemiologic data suggesting that another significant other-a spouse-may provide social support for the survival advantage of marrieds with cancer Goodwin, Hunt, Key, $\&$ Samet, 1987) or other illnesses (e.g., Berkman \& Syme, 1979; House, Robbins, \& Metzner, 1982).

It is unlikely that the qualities of therapeutic empathy, warmth, and genuineness evolve quickly when they are separate from an ongoing social relationship such as a marriage. The most demanding interventions were the individual support of Linn (Linn et al., 1982) and the group support of Spiegel, Bloom, and Yalom (1981); in fact, these interventions were so different (e.g., at least 75 hours in Speigel) that they might best be considered in their own context. This magnitude of intervention is 6-7 times that of any other. Intervention for the Linn subjects may not have been as long, in part because the lung cancer participants died more rapidly. Despite potentially similar intensities of intervention, the remarkable survival advantage found by Spiegel was not replicated by Linn. Aside from the many methodology differences of the studies, one disease factor accounting for the discrepancy might be the shorter survival "window" for metastatic lung cancer patients in contrast to metastatic breast cancer patients. (Five-year survival rates are 14\% and 72\%, respectively, for initial Stage III disease and 2\% and 19\%, respectively, for initial Stage IV disease [Boring, Squires, \& Tong, 1992].) That is, if "psychological factors" such as those accruing from long-term improvements in adjustment, continued gains from long-term therapy participation, or a significant therapeutic relationship influence survival through changes in health behaviors and/or immune system enhancement, the differences may be detected only when the "dose" of the factor is sufficient and when the disease provides a reasonable time interval for the factor to contribute.

\section{Future Directions}

Although intervention research with medically ill individuals is often not construed as psychotherapy outcome research, the same domains_-patients; therapist and treatments; assessment strategy, outcome criteria, and tactical selection of research designs-are relevant. In addition, the important role of disease/treatment variables as moderators for outcome require description and control. All of these variables have been considered in the above review; I turn next to their consideration for future research directions.

\section{Patient Variables}

Attention to three classes of variables-sociodemographics, premorbid status, and individual differences - of study subjects is needed. For all, description is essential, and "manipulation" as factors in a design would move the field forward. First, we begin with sociodemographic 
variables—age, race, gender, education, and income-as their importance is usually ignored despite their general role as potential mediators for health-promoting or health-damaging behaviors (Matthews, 1989). Specifically for cancer, a clear relationship to disease risk has been found with age, with a consistent increase in the incidence rates across races, sexes, and cancer sites. Furthermore, there are disproportionate death rates for the elderly: the largest cancer burden is borne by those 55 years and older, and the increase is dramatic after age 65 . Despite the latter, when emotional distress from cancer is considered, age is negatively correlated with distress such that "younger" patients are more distressed than "older." (Vinokur et al., 1989, contrasted women age 64 or less with those over 65 years who had been treated for breast cancer; Cassileth et al., 1984, found similar age-related adjustment patterns in six chronic illness groups.) Also, if individuals become physically impaired from the disease, younger patients experience significantly greater deterioration in their mental health and wellbeing than similarly impaired older patients (Vinokur, Threatt, Vinokur-Kaplan, \& Satariano, in press). To summarize, although the majority of cancer patients will be "older," "younger" patients are at greater risk for adjustment difficulties. The studies reviewed seldom considered whether or not the sample was nationally representative, and, furthermore, "younger" cancer patients (who may be at "higher" risk for psychological distress) were disproportionately sampled.

There are epidemiologic data on cancer risk for the remaining sociodemographic factors, but there are few supporting psychologic data. Considering race, when Blacks and Whites are compared, Blacks have a greater incidence than Whites across the majority of cancer sites (exceptions include bladder cancer, breast cancer in women over 40 years, colon, lung, and ovary for women; Christensen \& Baquet, in press). Current incidence rates for Hispanics are not representative (e.g., data from Hispanics in the Southwest are available, but they underestimate the rates for Puerto Ricans and Cubans); similar problems exist for the database on Native Americans, a situation compounded by their heterogeneity (tribal differences). Considering mortality, Blacks have the highest mortality rate (211.0) and lowest all-site survival rate (37.8) compared with Whites (166.2 and 50.3, respectively). In summary, Blacks have a disproportionate cancer burden, and that for Hispanics and Native Americans is negative but less clear. Despite this racial distribution of the disease, there are few descriptive data on the psychosocial responses of non-Whites; few non-Whites have participated in the intervention investigations, and efforts to remedy these situations are recent (e.g., Bal, 1992; Freeman, 1989). The psychosocial responses to cancer of Blacks or other minorities may not be identical to that of Whites; if they are dissimilar, their potential risk for adjustment difficulties may be increased because the health care system (including psychologists armed with interventions) may be less attuned to their needs.

For socioeconomic status (SES), the proxy measures of family income and educational level might be used. There is a relationship between both variables and age-adjusted cancer incidence and survival. The discouraging cancer results for some racial groups, Blacks in particular, appear to be due in large part to SES (Baquet, Horm, Gibbs, \& Greenwald, 1991) and are likely to be the health consequences that befall the nation's poor (Freeman, 1989). Thus, examining the psychologic responses of various socioeconomic groups necessitates consideration of the circumstances that may arise from a lack of education, unemployment, substandard housing, poor nutrition, risk-promoting life-style and behavior, diminished access to health care, and others-all variables to consider in the context of one more stressor, cancer.

Within the rubric of premorbid status, both physical and mental health, are considered. Existing health conditions (with their corresponding treatments) often limit the cancer treatments that can be offered as well as their efficacy. In addition, some chronic conditions serve as risk factors for cancer (e.g., obesity is a risk-factor for endometrial cancer; alcohol consumption is linked to cirrhosis, and cirrhosis is linked to liver cancer). Regardless of the linkage, 
comorbidity will result in greater decrements in social and role functioning, mental health, and health perceptions (Stewart et al., 1989). Psychiatric history, particularly depressive disorders, places an individual at increased risk for depression following cancer diagnosis (i.e., beyond the $6 \%$ base rate for depression in the healthy population). Thus, the presence of previous physical or mental health conditions may increase risk for adjustment difficulties following cancer and may interact with the efficacy of interventions. This conclusion is consistent with survey data indicating that the effects of depressive symptoms and chronic medical conditions (e.g., hypertension, diabetes, arthritis, gastrointestinal disorder) on functioning are additive, resulting in twice the reduction in social adjustment and physical functioning as either condition alone (Wells et al., 1989). Of all the studies reviewed, few noted any strategy for dealing with either of these issues in the context of subject recruitment. If these factors are allowed to vary and positive outcomes are found for an intervention, we have greater confidence in the robustness of the psychologic observations. However, variation rather than control may also make more difficult the clarification of biologic mechanisms.

This review serves as testimony for the generally positive effects of psychological interventions for cancer patients, and thus the literature would be moved forward with an examination of psychological/behavioral individual differences as a factor in research designs. Although there are potentially several relevant ones, three are highlighted.

1. Existing social networks/support differences among patients or interventions that differ in the provision of social support would provide important data. Future study will be assisted by the advances in the assessment of social support, but for adults a straightforward proxy variable may be marital status. Married persons live longer and have lower mortality for al most every major cause of death in comparison with single never married, separated, widowed, or divorced persons (Ortmeyer, 1974). More specifically, population-based studies of adults with cancer indicate that unmarrieds have a decreased overall survival because of initial presentations with more advanced disease, a higher likelihood of being untreated for cancer, and, after adjustment for both factors, a poorer treatment response still remains for unmarrieds (Goodwin et al., 1987). Given the incidence rates for the disease, the unmarried group is also likely to be "older." What might be the mechanisms for such a risk status? The two most likely candidates are the benefits that accrue from the higher SES of marrieds (see discussion above) and social support. The importance of social support has been underscored in large community cohort studies that have controlled for income (e.g., Berkman \& Syme, 1979; House et al., 1982). In addition to the role of social support as an individual difference variable, the discussion above and other authors (Broadhead \& Kaplan, 1991; Taylor, Falke, Shoptaw, \& Lichtman, 1986) have highlighted its potential contribution as a factor in moderating outcome along with other intervention components.

2. Consideration of the contribution of earlier (prediagnosis) or new stresses to intervention effectiveness would be important. Although there is no straightforward examination of this issue in the cancer literature, there is ample evidence for the moderating role of stress for both psychological and health outcomes. Convincing evidence for the importance of stress on an illness endpoint comes from Cohen, Tyrrell, and Smith (1991). Using a novel strategy to quantify "stress" (a composite index of negative life events, perceptions of one's coping capabilities, and negative affect), it related in a dose-response fashion to common cold infections, a pattern replicated across five cold viruses. Previous data have confirmed that acute (KiecoltGlaser et al., 1984) and chronic stressors (Kiecolt-Glaser et al., 1991) adversely affect health and immunity in otherwise healthy adults. Thus, we might hypothesize that the effects of ongoing or new stressors for cancer patients may adversely affect direct or indirect intervention outcomes or the psychological or biologic mechanisms. 
3. Finally, study of psychological individual differences remains important. Although this suggestion is often made, it is more difficult to specify which differences, as both positive and negative findings exist for the majority of likely candidates. However, dimensions under current study with cancer groups that may hold promise include relatively stable coping processes (e.g., Charles Carver's study of optimismpessimism; Scheier \& Carver, in press) and positive affects (e.g., Levy, Lee, Bagley, \& Lippman, 1988; but see Zonderman, Costa, \& McCrae, 1989, for contrary data). Other studies that have highlighted adverse effects of negative emotions, specifically anger (either expression or control; e.g., Greer, Morris, \& Pettingale, 1979; Derogatis, Abeloff, \& Melisartos, 1979), might consider the broader construct of neuroticism as one possible basis for these findings.

\section{Cancer Variables}

This article begins by raising and attempting to dispel a "uniformity myth" in research with cancer patients and considers the "magnitude" of disease/treatment as an important factor in outcome. Although this view of the complexity of cancer and its treatment is not without problems (e.g., the direct effects of one aspect can be confounded by the other), the research summaries suggest the utility of such a classification at the present time. On the broadest levels, important medical decisions at diagnosis include the determination of site, stage of disease, and the histopathologic classification, including grading and cell type. Medical judgments about the disease and selection of treatment(s) consider these variables as well as many others, including the aggressiveness and predictability of the disease, the medical morbidity and mortality of the therapy, overall cure rate, and physician/institution experience in treating the disease (e.g., see Osteen, Steele, Menck, \& Winchester, 1992, for an interesting example). Even when study samples having similar disease characteristics can be found, the subjects may still not receive similar therapies or may be more or less eligible for medical interventions to reduce psychological/behavioral risk. Obvious examples of the latter are the differential availability or selection of breast-preserving therapy or breast reconstruction and the control of disease or treatment symptomatology (e.g. control of nausea/vomiting from chemotherapy with anti-emetic or behavioral pain control strategies). ${ }^{3}$ Data have suggested that the availability of such interventions is risk reducing (e.g., examples of rehabilitative medical efforts include breast reconstruction, maxillofacial prosthetics for the head/neck patients, vaginal reconstruction for pelvic exenteration patients, or penile implants for men with prostate cancer), although they are not panaceas. Whereas some studies acknowledged the general importance of some of these variables in the form of stringent recruitment criteria (e.g., Fawzy, Cousins, et al., 1990; Fawzy, Kemeny, et al., 1990), the majority did not.

Future research must wrestle with this difficult issue. As a beginning, more comprehensive disease and treatment description of study participants is needed. Next, study of these variables as factors in a design using strategies such as those suggested here would provide data to identify risk groups at or shortly after the time of diagnosis, as even the most cost-effective interventions will not be available to or appropriate for all cancer patients.

\section{Therapists and Therapeutic Techniques}

Important for advancing the field is description, documentation, and testing mechanism(s) of the therapies studied. Few investigators publish supplementary clinical articles discussing aspects of the intervention (see Gordon et al., 1980, or Spiegel et al., 1981, for exceptions) or note that intervention manuals are available on request (see Fawzy, Cousins,' et al., 1990, or Gordon et al., 1980, for exceptions). Only the Gordon study documented the content of the

\footnotetext{
${ }^{3}$ One group addressing this issue consists of investigators who are studying efforts to reduce symptoms of chemotherapy. Ratings of the emetogenic potential of the drugs have been used to predict outcome (Carey \& Burish, 1988).
} 
therapy sessions, total length per subject, and the interventions employed. With few exceptions, studies did not provide process measures of intervention components (see Telch and Telch, 1986, for their monitoring of homework assignments). Specification of the theoretical bases or the mechanisms by which interventions are to achieve their effectiveness would clarify the details of complex interventions, detail the conditions necessary for replication, and advance theory. Finally, it is suggested that "nonspecifics" require study as they may play an important role in moderating outcome in studies of high-risk patients.

\section{Assessment Strategies and Outcome Criteria}

By definition, the intent of psychological intervention research is clinical improvement of distressing psychological states or behavior. Other intentions, such as making theoretical contributions or having indirect effects on other life areas, require additional outcome criteria and data collection. At a minimum, assessment for intervention studies in cancer may require familiarity with several nonoverlapping methodologies, including assessment of affective distress and psychopathology, "quality-of-life" measures, and relevant medical (i.e., biologic, disease, or treatment) endpoints, to note the obvious.

Considering the range of assessment measures, it appears that psychological interventions for cancer patients have been expected to provide "all things (outcomes) to all people." Beyond the direct impact on distressing states or behaviors, the outcome net has been cast widely (and perhaps wildly) to tap internal, stable patient characteristics (e.g., self-esteem), intimate relationships (e.g., marital adjustment), social relationships, major life areas (e.g., hours of employment), physical activity, disease and treatment-related symptoms, biologic responses (e.g., endocrine/immune variables), and finally disease end-points. A number of perspectives have encouraged this diversity and complexity, including advocates of convergent operations, the advocates of divergent operations, the view that outcome research needs to document the mechanism (and more specifically, the biologic mechanism) of treatment efficacy, and the belief that casting a wide net is essential when knowledge is limited (e.g., see Ware, 1984, for an example). Whatever the rationale, this scenario might be balanced by other perspectives, such as the burden on patients, the economic cost of the research, and the appreciation that a single study need not address all issues.

The contributions of psychology to cancer research may be linked in part to the continued refinement of creative, feasible, and reliable/valid assessment methods. For example, this fact is made obvious by the accelerating attention to and press for quality-of-life assessment in clinical trials research (see Aaronson, 1989; Olschewski \& Schumacher, 1990). It is important to note that significant progress has been made in the decade. Whereas early panels focused on assessment as the to-be-tackled problem (see American Cancer Society, 1984), recent panels have acknowledged the general success in the use of existing measures for many aspects of adjustment (e.g., see Burish, 1991a, 1991b; American Cancer Society, 1992).

\section{A Final Comment on Impediments: Funding for Psychological Intervention Research With Cancer Patients}

Complexities confronting the researcher studying psychological interventions for cancer patients were detailed. Other articles can provide discussions of many impediments, such as the training circumstances, for example, that have resulted in relatively few psychologists' having a primary focus on cancer (see Andersen et al., 1989, or Burish, 1991b). However, it is clear that the magnitude of clinical psychology's (or behavioral science's) contribution to addressing the cancer problem has been constricted by the lack of attention to and funding of this research by federal agencies. Even "modest" interventions are time- and labor-intensive undertakings made possible only with external funding. This reality, coupled with cancer as the number two cause of death of Americans, makes the level of previous research support 
disheartening. In addition, the data suggest that the funding for cancer rehabilitation research has worsened in the decade. For example, Ferlic et al. (1979) reported the first randomized psychological intervention study with cancer patients in 1979. Counting the 18 major investigations since then, only $16 \%$ of the studies were reported in the last 5 years. Although what is studied is driven by the quality of grant applications submitted, it is difficult to conceive that the disciplines of psychology, psychiatry, and nursing, for example, could not (or did not) submit more than 18 fundable intervention studies in the last 13 years. The thrust of this article is to underscore the meaningful differences psychological interventions can make for cancer patients, but I will end with the concern that their impact will be negligible without psychology also advocating for their importance to policy makers and funding adgencies.

\section{Acknowledgments}

I would like to thank individuals who provided constructive comments on drafts of the article: Joan Bloom, John Cacioppo, Mark Elliot, Janice Kiecolt-Glaser, Michael Vasey, and two anonymous reviewers. Susan Doyle-Mirzadeh assisted with the literature search.

\section{References}

Aaronson NK. Quality of life assessment in clinical trials: Methodologic issues. Controlled Clinical Trials 1989;10:195s-208s. [PubMed: 2605968]

American Cancer Society. Proceedings of the working conference on methodology in behavioral and psychosocial cancer research-1983. Cancer 1984;53(Suppl 10):2217-2384. [PubMed: 6367936]

American Cancer Society. Cancer facts \& figures: 1992. Atlanta, GA: Author; 1992.

Andersen BL. Health psychology's contribution to addressing the cancer problem: Update on accomplishments. Health Psychology 1989;8:683-703. [PubMed: 2700343]

Andersen BL, Anderson B, deProsse C. Controlled prospective longitudinal study of women with cancer: I. Sexual functioning outcomes. Journal of Consulting and Clinical Psychology 1989a;57:683-691. [PubMed: 2600238]

Andersen BL, Anderson B, deProsse C. Controlled prospective longitudinal study of women with cancer: II. Psychological outcomes. Journal of Consulting and Clinical Psychology 1989b;57:692-697. [PubMed: 2600239]

Andersen BL, Beck G, Ouelette-Kobasa S, Revenson TA, Temoshok L. Directions for a psychology research agenda in cancer. Health Psychology 1989;8:753-760. [PubMed: 2700347]

Andrykowski MA. The role of anxiety in the development of anticipatory nausea in cancer chemotherapy: A review and synthesis. Psychosomatic Medicine 1990;52:458-475. [PubMed: 2204952]

Axtell, LM.; Asire, AJ.; Meyers, MH., editors. Cancer patient survival (Report No. 5, NCI Pub. No. NIH 771-992). Washington, DC: U.S. Government Printing Office; 1976.

Bal DG. Cancer in African Americans. Ca-A Cancer Journal for Clinicians 1992;42:5-6. [PubMed: 1728339]

Baquet CR, Horm JW, Gibbs T, Greenwald P. Socioeconomic factors and cancer incidence among Blacks and Whites. Journal of the National Cancer Institute 1991;83:551-557. [PubMed: 2005640]

Beck A, Ward C, Mendelson M, Mock J, Erbaugh J. An inventory for measuring depression. Archives of General Psychiatry 1961;4:561-571. [PubMed: 13688369]

Berkman LF, Syme SL. Social networks, host resistance, and mortality: A 9-year follow-up study of Alameda County residents. American Journal of Epidemiology 1979;109:186-204. [PubMed: 425958]

Bernstein IL. Etiology of anorexia in cancer. Cancer 1986;58:1881-1886. [PubMed: 3463394]

Beutler, LE.; Crago, M.; Arizmendi, TG. Therapist variables in psychotherapy process and outcome. In: Garfield, SL.; Bergin, AE., editors. Handbook of psychotherapy and behavior change. Vol. 3. New York: Wiley; 1986. p. 257-311.

Bloom JR. Psychological response to mastectomy. Cancer 1987;59:189-196. [PubMed: 3491668]

Boring CC, Squires TS, Tong T. Cancer statistics, 1992. Ca-A Cancer Journal for Clinicians 1992;42(1): 19-38. [PubMed: 1728335] 
Broadhead WE, Kaplan BH. Social support and the cancer patient: Implications for future research and clinical care. Cancer 1991;67:794-799. [PubMed: 1986847]

Burish TG. Behavioral and psychosocial research in cancer: Building on the past, preparing for the future. Cancer 1991a;67:865-867. [PubMed: 1986860]

Burish TG. Progress in psychosocial and behavioral cancer research: The need for enabling strategies. Cancer 1991b;67:860-864. [PubMed: 1986859]

Cain EN, Kohorn EI, Quinlan DM, Latimer K, Schwartz PE. Psychosocial benefits of a cancer support group. Cancer 1986;57:183-189. [PubMed: 3079660]

Capone MA, Good RS, Westie KS, Jacobsen AF. Psychosocial rehabilitation of gynecologic oncology patients. Archives of Physical Medicine and Rehabilitation 1980;61:128-132. [PubMed: 7369850]

Carey MP, Burish TG. Etiology and treatment of the psychological side effects associated with cancer chemotherapy. Psychological Bulletin 1988;104:307-325. [PubMed: 3062654]

Carnrike CLM, Carey MP. Assessing nausea and vomiting in adult chemotherapy patients: Review and recommendations. Annals of Behavioral Medicine 1990;12:79-85.

Cassileth PA, Cassileth BR. Clinical care of the terminal cancer patient: Part 1. Medical Times 1983 March;:57s-66s.

Cassileth BR, Lusk EJ, Strouse TB, Miller DS, Brown LL, Cross PA. A psychological analysis of cancer patients and their next-of-kin. Cancer 1985;55:72-76. [PubMed: 3965087]

Cassileth BR, Lusk EJ, Strouse TB, Miller DS, Brown LL, Cross PA, Tenaglia AN. Psychosocial status in chronic illness: A comparative analysis of six diagnostic groups. New England Journal of Medicine 1984;311:506-511. [PubMed: 6749208]

Cassileth BR, Lusk EJ, Tenaglia AN. Patients' perceptions of the cosmetic impact of melanoma resection. Plastic and Reconstructive Surgery 1983;71:73-75. [PubMed: 6849025]

Cella DF, Orofiamma B, Holland JC, Silberfarb PM, Tross S, Feldstein M, Perry M, Maurer LH, Comis R, Oraz EJ. The relationship of psychological distress, extent of disease, and performance status in patients with lung cancer. Cancer 1987;60:1661-1667. [PubMed: 3621136]

Cella DF, Tross S. Psychological adjustment to survival from Hodgkin's disease. Journal of Consulting and Clinical Psychology 1986;54:616-622. [PubMed: 3771879]

Christensen DN. Postmastectomy couple counseling: An outcome study of a structured treatment protocal. Journal of Sex \& Marital Therapy 1983;9:266-274. [PubMed: 6663643]

Christenson GM, Baquet C. What is known about the conditions and behavior of those people disproportionately affected by cancer? Cancer Prevention. in press

Cohen S, Tyrrell DA, Smith AP. Psychological stress in humans and susceptibility to the common cold. New England Journal of Medicine 1991;325:606-612. [PubMed: 1713648]

Davis H. Effects of biofeedback and cognitive therapy on stress in patients with breast cancer. Psychological Reports 1986;59:967-974. [PubMed: 3809353]

de Haes JCJM, van Oostrom MA, Welvaart K. The effect of radical and conserving surgery on quality of life of early breast cancer patients. European Journal of Surgical Oncology 1986;12:337-342. [PubMed: 3780987]

Derogatis, LR. SCL-90: Administration, scoring, and procedures manual-I for the (R)evised Version. Baltimore: Johns Hopkins University School of Medicine; 1977.

Derogatis LR, Abeloff MD, Melisartos N. Psychological coping mechanisms and survival time in metastatic breast cancer. Journal of the American Medical Association 1979;242:1504-1508. [PubMed: 470087]

Devlen J, Maguire P, Phillips P, Crowther D, Chambers H. Psychological problems associated with diagnosis and treatment of lymphomas: 1 . Retrospective study and 2. Prospective study. British Medical Journal 1987;295:953-957. [PubMed: 3119123]

Edgar L, Rosberger Z, Nowlis D. Coping with cancer during the first year after diagnosis: Assessment and intervention. Cancer 1992;69:817-828. [PubMed: 1730131]

Endicott J, Spitzer RL. A diagnostic interview: The Schedule for Affective Disorders and Schizophrenia. Archives of General Psychiatry 1978;35:837-844. [PubMed: 678037]

Eyre HJ, Ward JH. Control of cancer chemotherapy-induced nausea and vomiting. Cancer 1984;54:26422648. [PubMed: 6498755] 
Fawzy FI, Cousins N, Fawzy N, Kemeny ME, Elashoff R, Morton D. A structured psychiatric intervention for cancer patients: 1 . Changes over time in methods of coping and affective disturbance. Archives of General Psychiatry 1990;47:720-725. [PubMed: 2378543]

Fawzy FI, Kemeny ME, Fawzy N, Elashoff R, Morton D, Cousins N, Fahey JL. A structured psychiatric intervention for cancer patients: 1. Changes over time in immunological measures. Archives of General Psychiatry 1990;47:729-735. [PubMed: 2143062]

Ferlic M, Goldman A, Kennedy BJ. Group counseling in adult patients with advanced cancer. Cancer 1979;43:760-766. [PubMed: 421192]

Forester B, Kornfeld DS, Fleiss JL. Psychotherapy during radiotherapy: Effects on emotional and physical distress. American Journal of Psychiatry 1985;142:22-27. [PubMed: 3966583]

Freeman HP. Cancer in the socioeconomically disadvantaged. Ca-A Cancer Journal for Clinicians 1989;39(5):266-288. [PubMed: 2513099]

Goodwin JS, Hunt WC, Key CR, Samet JM. The effect of marital status on stage, treatment, and survival of cancer patients. Journal of the American Medical Association 1987;258:3125-3130. [PubMed: 3669259]

Gordon WA, Freidenbergs I, Diller L, Hibberd M, Wold C, Levine L, Lipkins R, Ezrachi O, Lucido D. Efficacy of Psychosocial intervention with cancer patients. Journal of Consulting and Clinical Psychology 1980;48:743-759. [PubMed: 7440831]

Greer S, Morris T, Pettingale KW. Psychological response to breast cancer: Effect on outcome. Lancet 1979;2:785-787. [PubMed: 90871]

Heinrich RL, Coscarelli-Schag C. Stress and activity management: Group treatment for cancer patients and their spouses. Journal of Consulting and Clinical Psychology 1985;53:439-446. [PubMed: 4031198]

Heinrich RL, Coscarelli-Schag C, Ganz PA. Living with cancer: The Cancer Inventory of Problem Situations. Journal of Clinical Psychology 1984;40:972-980. [PubMed: 6480863]

House JS, Robbins C, Metzner HL. The association of social relationships and activities with mortality: Prospective evidence from the Tecumseh community health study. American Journal of Epidemiology 1982;116:123-140. [PubMed: 7102648]

Houts PS, Whitney CW, Mortel R, Bartholomew MJ. Former cancer patients as counselors of newly diagnosed cancer patients. Journal of the National Cancer Institute 1986;76:793-796. [PubMed: 3457967]

Hughson AV, Cooper AF, McArdle CS, Smith DC. Psychological impact of adjuvant chemotherapy in the first two years after mastectomy. British Medical Journal of Clinical Research 1986;293:12681271.

Jacobs C, Ross RD, Walker IM, Stockdale FE. Behavior of cancer patients: A randomized study of the effects of education and peer support groups. American Journal of Clinical Oncology 1983;6:347353. [PubMed: 6342360]

Karnofsky, DA.; Burchenal, JH. The clinical evaluation of chemotherapeutic agents in cancer. In: Macleod, CM., editor. Evaluation of chemotherapeutic agents. New York: Columbia University Press; 1949. p. 191-205.

Kazdin, A. The evaluation of psychotherapy: Research design and methodology. In: Garfield, SL.; Bergin, AE., editors. Handbook of psychotherapy and behavior change. Vol. 3. New York: Wiley; 1986. p. 23-68.

Kiecolt-Glaser JK, Dura J, Speicher C, Trask B, Glaser R. Spousal caregivers of dementia victims: Longitudinal changes in immunity and health. Psychosomatic Medicine 1991;53:345-362. [PubMed: 1656478]

Kiecolt-Glaser JK, Garner WK, Speicher C, Penn GM, Holliday J, Glaser R. Psychosocial modifiers of immunocompetence in medical students. Psychosomatic Medicine 1984;46:7-14. [PubMed: 6701256]

Kiecolt-Glaser JK, Glaser R, Williger D, Stout J, Messick G, Sheppard S, Richer D, Romisher SC, Briner W, Bonnell G, Donnerberg R. Psychosocial enhancement of immunocompetence in a geriatric population. Health Psychology 1985;4:25-41. [PubMed: 2990890] 
Kolotkin, RL.; Johnson, M. Crisis intervention and measurement of treatment outcome. In: Lambert, MJ.; Christensen, ER.; DeJulio, SS., editors. The assessment of psychotherapy outcome. New York: Wiley; 1983. p. 132-159.

Levy SM, Lee J, Bagley C, Lippman M. Survival hazards analysis in first recurrent breast cancer patients: Seven-year follow-up. Psychosomatic Medicine 1988;50:520-528. [PubMed: 3186895]

Linn MW, Linn BS, Harris R. Effects of counseling for late stage cancer patients. Cancer 1982;49:10481055. [PubMed: 7059922]

Maguire P, Brooke M, Tail A, Thomas C, Sellwood R. The effect of counselling on physical disability and social recovery after mastectomy. Clinical Oncology 1983;9:319-324. [PubMed: 6362943]

Maguire P, Hopwood P, Tarrier N, Howell T. Treatment of depression in cancer patients. Acta Psychiatric Scandia 1985;72(Suppl 320):81-84.

Maguire P, Tail A, Brooke M, Thomas C, Sellwood R. Effect of counselling on the psychiatric morbidity associated with mastectomy. British Medical Journal 1980;281:1454-1456. [PubMed: 7192170]

Matthews KA. Are sociodemographic variables markers for psychological determinants of health? Health Psychology 1989;8:641-648. [PubMed: 2700340]

McCorkle R, Benoliel JQ, Donaldson G, Georgiadou F, Moinpour C, Goodell B. A randomized clinical trial of home nursing care for lung cancer patients. Cancer 1989;64:1375-1382. [PubMed: 2670188]

McNair, DM.; Lorr, M.; Droppleman, LF. Profile of Mood States. San Diego, CA: Educational and Industrial Testing Service; 1971.

Meyerowitz BE, Watkins IK, Sparks FC. Psychosocial implications of adjuvant chemotherapy: A twoyear follow-up. Cancer 1983;52:1541-1545. [PubMed: 6616414]

Morrow GR. Chemotherapy-related nausea and vomiting: Etiology and management. Ca-A Cancer Journal for Clinicians 1989;39:89-104. [PubMed: 2495160]

Morrow GR, Dobkin PL. Anticipatory nausea and vomiting in cancer patients undergoing chemotherapy treatment: Prevalence, etiology, and behavioral interventions. Clinical Psychology Review 1988;8:517-556.

Olschewski M, Schumacher M. Statistical analysis of quality of life data in cancer clinical trials. Statistics in Medicine 1990;9:749-763. [PubMed: 2218178]

Ortmeyer, CF. Variations in mortality, morbidity, and health care by marital status. In: Erhardt, LL.; Berlin, JE., editors. Mortality and morbidity in the United Slates. Cambridge, MA: Harvard University Press; 1974. p. 159-184.

Osteen RT, Steele GD, Menck HR, Winchester DP. Regional differences in surgical management of breast cancer. Ca-A Cancer Journal for Clinicians 1992;42:39-43. [PubMed: 1728336]

Parloff, MB.; Waskow, IE.; Wolfe, BE. Research on therapist variables in relation to process and outcome. In: Garfield, SL.; Bergin, AE., editors. Handbook of psychotherapy and behavior change. Vol. 2. New York: Wiley; 1978. p. 233-282.

Paul, GL. Behavior modification research: Design and tactics. In: Franks, CM., editor. Behavior therapy: Appraisal and status. New York: McGraw-Hill; 1969. p. 29-62.

Pennebaker JW, Kiecolt-Glaser JK, Glaser R. Disclosure of traumas and immune function: Health implications for psychotherapy. Journal of Consulting and Clinical Psychology 1988;56:239-245. [PubMed: 3372832]

Redd WH, Andrykowski M. Behavioral intervention in cancer treatment: Controlling aversive reactions to chemotherapy. Journal of Clinical and Consulting Psychology 1982;50:1018-1029.

Schain W, Edwards BK, Gorrell CR, deMoss EV, Lippman ME, Gerber LH, Lichter AS. Psychosocial and physical outcomes of primary breast cancer therapy: Mastectomy vs. excisional biopsy and irradiation. Breast Cancer Research and Treatment 1983;3:377-382. [PubMed: 6365210]

Scheier MF, Carver CS. Effects of optimism on psychological and physical well-being: Theoretical overview and empirical update. Cognitive Therapy and Research. in press

Silberberg E, Lubera JA. Cancer statistics, 1989. Ca-A Cancer Journal for Clinicians 1989;39:3-20. [PubMed: 2492874]

Spiegel D, Bloom JR. Group therapy and hypnosis reduce metastatic breast carcinoma pain. Psychosomatic Medicine 1983;45:333-339. [PubMed: 6622622] 
Spiegel D, Bloom JR, Kraemer HC, Gottheil E. Effect of psychosocial treatment on survival of patients with metastatic breast cancer. Lancet 1989 October 14;:888-891. [PubMed: 2571815]

Spiegel D, Bloom JR, Yalom I. Group support for patients with metastatic cancer: A randomized outcome study. Archives of General Psychiatry 1981;38:527-533. [PubMed: 7235853]

Spiegel D, Glafkedes MC. Effects of group confrontation with death and dying. International Journal of Group Psychotherapy 1983;33:433-447. [PubMed: 6642804]

Spiegel D, Yalom ID. A support group for dying patients. International Journal of Group Psychotherapy 1978;28:233-245. [PubMed: 631956]

Spielberger, CD.; Gorsuch, RL.; Lushene, RE. Manual for the State-Trait Anxiety Inventory. Palo Alto, CA: Consulting Psychologists Press; 1970.

Stewart AL, Greenfield S, Hays RD, Wells K, Rogers WH, Berry SD, McGlynn EA, Ware JE. Functional status and well-being of patients with chronic conditions: Results from the Medical Outcomes Study. Journal of the American Medical Association 1989;262:907-913. [PubMed: 2754790]

Taylor SE, Falke RL, Shoptaw SJ, Lichtman RR. Social support, support groups, and the cancer patient. Journal of Consulting and Clinical Psychology 1986;54:608-615. [PubMed: 3771878]

Telch CF, Telch MJ. Group coping skills instruction and supportive group therapy for cancer patients: A comparison of strategies. Journal of Consulting and Clinical Psychology 1986;54:802-808. [PubMed: 3794024]

Thompson, L.; Andersen, BL.; DePetrillo, D. The psychological processes of recovery from gynecologic cancer. In: Coppleson, M.; Morrow, P.; Tattersall, M., editors. Gynecologic oncology. Vol. 2. Edinburgh, England: Churchill Livingstone; 1992. p. 1499-1505.

Turk DC, Fernandez E. On the putative uniqueness of cancer pain: Do psychological principles apply? Behavior Research and Therapy 1990;28:1-13.

Vinokur AD, Threatt BA, Caplan RD, Zimmerman BL. Physical and psychosocial functioning and adjustment to breast cancer: Long-term follow-up of a screening population. Cancer 1989;63:394405. [PubMed: 2910447]

Vinokur AD, Threatt BA, Vinokur-Kaplan D, Satariano WA. The process of recovery from breast cancer for younger and older patients: Changes during the first year. Cancer. in press

Ware, JE, Jr. Methodological considerations in the selection of health status procedures. In: Wenger, NK.; Mattson, ME.; Furberg, CD.; Elinson, J., editors. Assessment of quality of life in clinical trials of cardiovascular therapies. New York: Le Jacq; 1984. p. 84-95.

Weisman AD, Worden JW. The existential plight in cancer: Significance of the first 100 days. International Journal of Psychiatry in Medicine 1976-1977;7:1-15. [PubMed: 1052080]

Wells KB, Stewart A, Hays RD, Burnam A, Rogers W, Daniels M, Berry S, Greenfield S, Ware J. The functioning and well-being of depressed patients: Results from the Medical Outcomes Study. Journal of the American Medical Association 1989;262:914-919. [PubMed: 2754791]

Yalom, ID. The theory and practice of group psychotherapy. Vol. 2. New York: Basic Books; 1975.

Yates, JW.; McKegney, FP.; Kun, LE. Proceedings of the National Conference on Human Values and Cancer. New York: American Cancer Society; 1981. A comparative study of home nursing care of patients with advanced cancer; p. 207-218.

Zonderman AB, Costa P, McCrae RR. Depression as a risk for cancer morbidity and mortality in a nationally representative sample. Journal of the American Medical Association 1989;262:11911195. [PubMed: 2761060] 
Table 1

Cancer Characteristics That Contribute to the Individual's Risk for Psychological and Behavioral Morbidity

\begin{tabular}{lll}
\hline & & Cancer characteristics \\
\cline { 2 - 3 } Morbidity risk & Extent of disease & Magnitude of treatment \\
\hline Low & $\begin{array}{l}\text { Localized/Stage I or II at diagnosis } \\
\text { Moderate }\end{array}$ & $\begin{array}{l}\text { Usually single modality (e.g., surgery or } \\
\text { RT) }\end{array}$ \\
$\begin{array}{l}\text { Regional/Stage III at diagnosis; first } \\
\text { disease }\end{array}$ & $\begin{array}{l}\text { Often combination therapy (e.g., surgery } \\
\text { with RT for nodal disease; surgery with } \\
\text { adjuvant chemotherapy) }\end{array}$ \\
$\begin{array}{l}\text { Distant/Stage IV at diagnosis; first } \\
\text { recurrence for regional disease or all } \\
\text { stages of rapidly progressive } \\
\text { disease (e.g., lung or pancreatic } \\
\text { cancer) }\end{array}$ & $\begin{array}{l}\text { Possibility of surgery or RT for debulking/ } \\
\text { palliation. Systemic chemotherapy is likely; } \\
\text { possibility of invasive treatments for pain/ } \\
\text { symptom control }\end{array}$ \\
\hline
\end{tabular}

Note. $\mathrm{RT}$ = radiotherapy. 


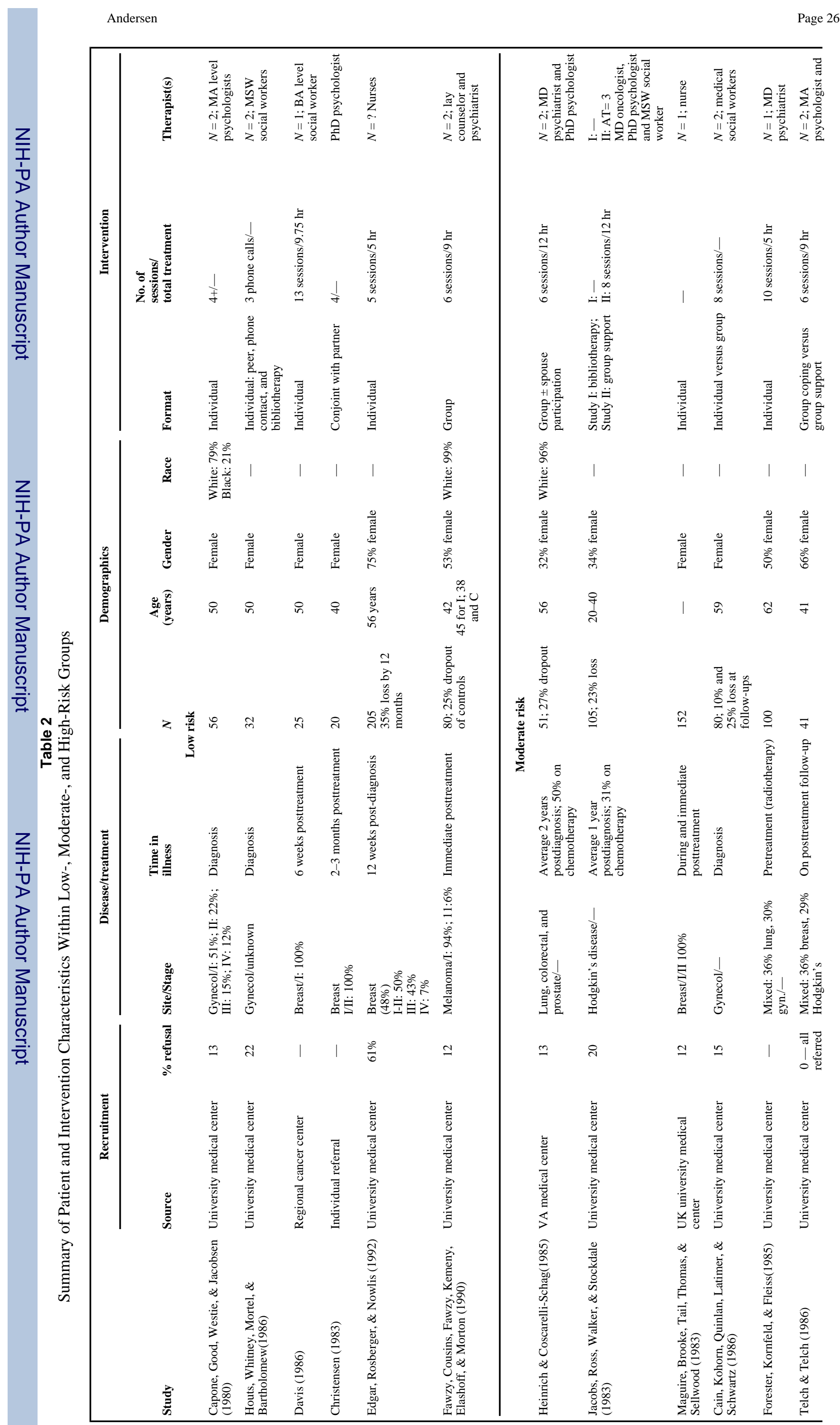

J Consult Clin Psychol. Author manuscript; available in PMC 2009 September 14. 


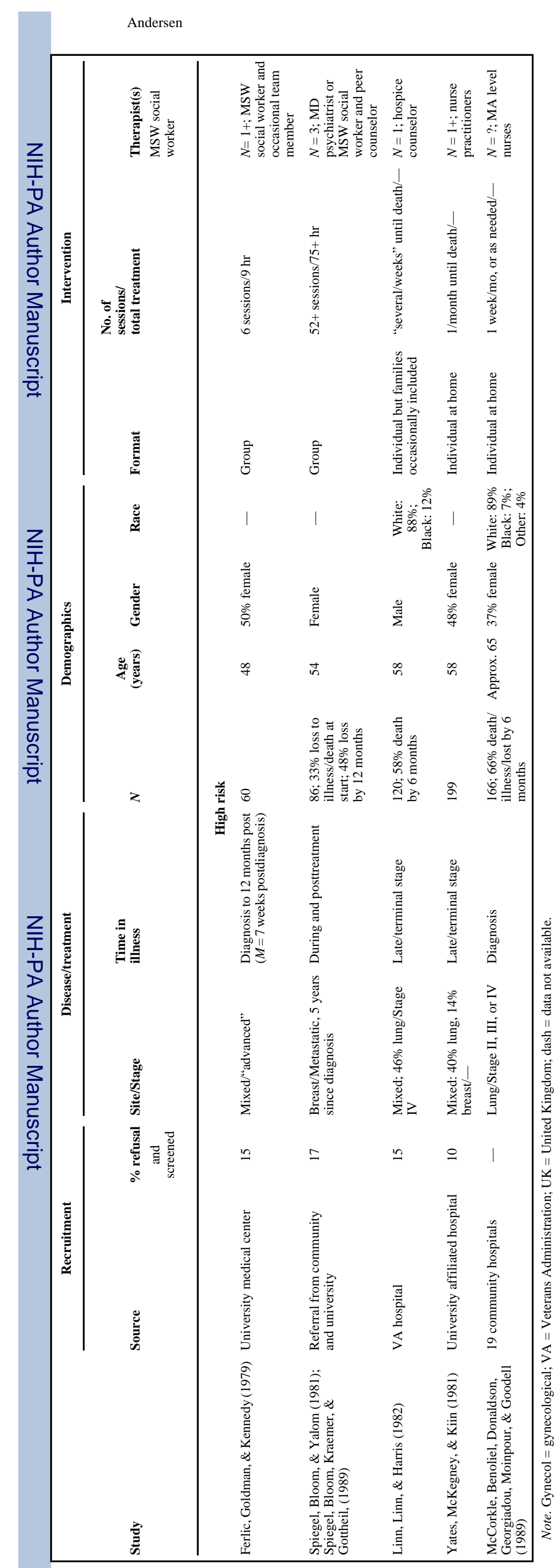

